BULLETIN Bulletin hispanique

HispaniQuE Université Michel de Montaigne Bordeaux

$116-2$ | 2014

Référentialité/autoréférentialité dans le roman espagnol contemporain : bilan et perspectives

\title{
Pío Baroja sobre Henri Bergson
}

en el carro chirriante tras los pasos de Kant

\section{Álvaro Cortina Urdampilleta}

\section{(2) OpenEdition \\ Journals}

\section{Edición electrónica}

URL: http://journals.openedition.org/bulletinhispanique/3634

DOI: 10.4000/bulletinhispanique.3634

ISBN: 979-10-300-0156-3

ISSN: 1775-3821

\section{Editor}

Presses universitaires de Bordeaux

\section{Edición impresa}

Fecha de publicación: 1 diciembre 2014

Paginación: 869-874

ISBN: 978-2-86781-963-6

ISSN: 0007-4640

Referencia electrónica

Álvaro Cortina Urdampilleta, «Pío Baroja sobre Henri Bergson », Bulletin hispanique [En línea],

116-2 | 2014, Publicado el 01 diciembre 2017, consultado el 30 abril 2019. URL : http://

journals.openedition.org/bulletinhispanique/3634; DOI : 10.4000/bulletinhispanique.3634 


\title{
Pío Baroja sobre Henri Bergson: en el carro chirriante tras los pasos de Kant
}

\author{
Álvaro Cortina Urdampilleta ${ }^{1}$ \\ Universidad Diego Portales - Chile
}

Dans cet article, nous analysons la vision qu'offre, dans ses essais, l'écrivain basque Pio Baroja de l'ouvre du philosophe français Henri Bergson. De plus, ses notes sur l'auteur de L'Évolution créatrice permettent d'apprécier la place qu'il lui accorde dans la philosophie contemporaine.

Mots-clés : Pío Baroja, Henri Bergson, Emmanuel Kant.

En este artículo analizamos la visión que el escritor vasco Pio Baroja tuvo de la obra del filósofo francés Henri Bergson en su obra ensayistica. Además, a través de sus valoraciones en torno al autor de La evolución creadora podremos ver el lugar que le concede dentro de la filosofía contemporánea.

Palabras claves: Pío Baroja, Henri Bergson, Immanuel Kant.

In this paper, we analyse the vision that the Basque writer Pio Baroja had of the work of the French philosopher Henri Bergson in his essays. In addition, through his notes upon the author of the Creative Evolution, we can see the place that he grants him within contemporary philosophy.

Keywords: Pío Baroja, Henri Bergson, Immanuel Kant.

E scribe Pío Baroja, en 1917, en Juventud, egolatría, en el apartado Los filósofos: "¿Por qué yo, hombre de poca tenacidad, he llegado a tener perseverancia bastante para leer unos libros difíciles, para los cuales no tenía preparación?» ${ }^{2}$. Nuestro objeto en este artículo será aunar las referencias al

1. Programa de doctorado en filosofía UDP-Leiden.

2. Pío Baroja, Juventud, egolatría, Taifa Editorial, Madrid, 1987, p. 86.

Bulletin Hispanique, Tome 116, n 2 - décembre 2014 - p. 869-874. 
filósofo francés Henri Bergson que Baroja fue sumando en su obra ensayística, con perseverancia de lector curioso de la filosofía. Su nombre se menciona en su narrativa (como, por ejemplo, en El gran torbellino del mundo ${ }^{3}$ ) y podríamos contar con opiniones útiles y pertinentes vertidas en sus novelas, como cuando Andrés Hurtado expone un punto de vista casi como de "portavoz» ${ }^{4}$ del propio Baroja diciendo que al lado de Kant y Schopenhauer, los autores franceses e ingleses son "carros pesados que marchan chirriando y sacando polvo" ${ }^{5}$. Pero hemos creído más conveniente seguir la consideración de Julián Marías sobre el escritor vasco. Marías separa las ideas como tales del «Baroja intelectual» de aquellas que encontramos en su novelística (un «Baroja artista»), abundante en juicios de valor que no tienen, según él, la consistencia de las ideas ("pseudoideas", las califica) ${ }^{6}$, ni tampoco su objeto, sino una naturaleza peculiar dentro de su peculiar estilo ficcional retórico.

José Corrales señala que «Bergson, aunque más celebrado que los otros pensadores franceses de la primera mitad de siglo, no pasa de ser, según Baroja, una especie de Ortega y Gasset a la francesa" ${ }^{7}$ y cita de las Memorias. Desde la última vuelta del camino: "Ortega, brillante como literato, no creo que sea un gran filósofo. El caso no es raro. Bergson también era superior como escritor que como filósofo»" . Un poco más adelante añade Corrales: «Sin que ello signifique que su arte literario se halle exento de los defectos comunes a ciertos literatos franceses: la falta de naturalidad y de interés»". Añade Corrales otras palabras del propio novelista en La horas solitarias, de 1918: «Se ha dado una fama a Bergson de escritor fácil y ameno. De este primer libro del filósofo francés, Essai sur les données immédiates de la conscience, no se puede decir que sea ameno ni fácil de entender» ${ }^{10}$.

Bergson forma parte de la generación modernista de «hombres venteadores y agoreros de la crisis» ${ }^{11}$, según expresión de Laín Entralgo, que influyen intelectualmente en los noventayochos y fue muy publicitada también en España su doctrina en torno al «élan vital» ${ }^{12}$. En Baroja, la opinión sobre su obra en

3. Pío Baroja, Obras Completas, v. I. Biblioteca Nueva, Madrid, 1968, p. 1126.

4. Carmen Iglesias, El pensamiento de Pío Baroja. Ideas centrales, Antigua Librería Robredo, México, 1963, p. 21.

5. Pío Baroja, El árbol de la ciencia, Cátedra, Madrid, 2001, p. 159.

6. Julián Marías, Cien años de Pio Baroja, Revista de Occidente, no 117, Diciembre, Madrid, 1972, p. 303: «...no son propiamente ideas». Este texto se incluiría después en el libro Literatura y generaciones, integrado por varios textos de Marías sobre literatura española. Espasa-Calpe, 1975, p. 127.

7. José Corrales Egea, Baroja y Francia, Taurus, Madrid, 1969, p. 214.

8. Pío Baroja, Obras Completas, v. VII, Biblioteca Nueva, Madrid, 1978, p. 820.

9. José Corrales Egea, Baroja y Francia, op. cit., p. 214.

10. Pío Baroja, Obras Completas, v. V, Biblioteca Nueva, Madrid, 1993, p. 299.

11. Pedro Laín Entraldo, La generación del noventa y ocho, Espasa-Calpe, Madrid, 1963, p. 68. El autor lo incluye en un grupo intelectual formado por Nietzsche, Dilthey e Ibsen. En una segunda ocasión (p. 151) Laín Entralgo habla de una serie de filósofos influidos en su juventud por el positivismo spenceriano, como Nietzsche, Bergson y Dilthey.

12. José Luis Abellán, Historia del pensamiento español, V. 7, Círculo de Lectores, Madrid, 
concreto se recoge en tres textos de un modo más detenido, y en otros dos de un modo tangencial y breve, más allá de la mera mención.

En el primer grupo tomamos una de las reseñas muy personales ${ }^{13}$ de Las horas solitarias, sobre Essai sur les données immédiates de la conscience, en el epígrafe del Libro tercero, Primavera, en Notas de un aprendiz de filósofo; otra referencia importante aparece en el apartado de Desde la última vuelta del camino titulada La intuición y el estilo, de 1948; por último, nos valdremos del ensayo Bergson y Freud publicado en La Nación de Buenos Aires el 21 de mayo de 1939, recogido después en La decadencia de la cortesía y otros ensayos, edición de 1956.

En la mentada recensión de 1918 sobre el Ensayo sobre los datos inmediatos de la conciencia, por Enrique Bergson, la primera obra y tesis doctoral del francés, se nos habla de éste como un pensador «a la moda estos últimos años» ${ }^{14}$. Después, resume: «Es decir, de los tres principios (Espacio, Tiempo y Causalidad) Kant intentó demoler el postulado de la Causalidad. Bergson, con el mismo objeto, intenta destruir el principio del tiempo como concepto puro y homogéneo» ${ }^{15}$. También leemos una apreciación general: «A juzgar por la fecha de su publicación, Bergson concibe su obra en un momento en que el mundo intelectual está harto de positivismo en filosofía y de realismo en arte» ${ }^{16}$.

Añade:

Así como Kant encontró falible el principio de Causalidad, Bergson quiere ir más lejos y encontrar falibilidad en el Tiempo. En esto, como decíamos antes, no hace más que exponer la trayectoria de Heráclito. [...] Explicar cómo de la no homogeneidad del Tiempo, de la no trascendencia, de la no pureza de este principio saca Bergson un posible indeterminismo científico, sería para mí un poco largo y difícil. [...] Ciertamente, también lo es para él, y el filósofo tiene que hacer grandes equilibrios sobre la cuerda floja, llevando la libertad en la espalda, y aun así no nos convence siempre de que su juego sea del todo limpio ${ }^{17}$.

En cierto modo, esta visión de Bergson como trapecista dialéctico, con una sombra de sospecha, aparece en el resto de textos que analizamos. Lo que sí es cierto es que, sobre la relación entre el francés y Heráclito ya encontramos una incontrovertible advertencia en una nota del propio Bergson, en su texto capital Introduction à la métaphysique, de 1903 (incluido posteriormente en La pensée et le mouvant, de 1934). En plena disquisición, coloca el filósofo esta nota para evitar un reiterado malentendido: "Comment a-t-on pu comparer cette doctrine à celle d'Héraclite?» ${ }^{18}$.

La cuestión heraclítea merece que nos detengamos una vez más, pues Carmen Iglesias señala una familiaridad intelectual de Pío Baroja con Heráclito ${ }^{19}$, y

1989 , p. 85 .

13. José-Carlos Mainer, Baroja, Taurus, Madrid, 2012, p. 236.

14. Pío Baroja, Obras Completas, v.V, Biblioteca Nueva, Madrid, 1993, p. 300.

15. Ibid., p. 303.

16. Ibid., p. 303.

17. Pío Baroja, Obras Completas, v.V, op. cit., p. 303.

18. Henri Bergson, Introduction à la métaphysique, PUF, Paris, 2011, p. 35.

19. Carmen Iglesias, El pensamiento de Pio Baroja. Ideas centrales, op. cit., 69. «Son filósofos 
habla del «desarrollo de la teoría heraclitiana» ${ }^{20}$ en el corpus barojiano, lo que no está del todo lejano al comentario de Julián Marías referido (pues las pseudoideas son pseudo-ideas en la medida en que generan un continuado flujo valorativo entre ideas e impresiones). Pero, a cuenta de esto, Iglesias parece desoír la advertencia de Henri Bergson en torno al peligro de relacionar su filosofía de sustancialización del tiempo a las cuestiones heraclíteas del devenir. Escribe la estudiosa, siguiendo la cuestión: «Lo demás fluye y evoluciona en una marcha constante. Por ello puede pensarse (como lo hizo Bergson) que hasta el tiempo evoluciona, cambia y tiene su devenir ${ }^{21}$.

Volvamos a los textos donde Baroja expone su postura sobre Bergson. En La intuición y el estilo, de 1948, hace referencia, nuevamente, a la querencia verbosa, a la sospecha de la mistificación del ya Nobel de Literatura Henri Bergson: «Según Bergson, las ideas de causa y de efecto, de espacio y de tiempo, nos esconden la realidad. ¿Qué realidad? Todo esto no es más que palabrería. Para el hombre no hay más realidad que la que dan los sentidos y la razón. Al parecer, Bergson quiere demostrar que fuera de esas ideas existe un élan vital más importante que las entelequias de la razón $»^{22}$.

Continúa: «Esto tiene todo el aire de un juego. Se puede pensar que estas nociones de causa y efecto, de tiempo y de espacio, de materia y de fuerza, son humanas; pero todas las demás nociones son también humanas [...] Salir de lo humano es imposible. ¿Qué es eso del élan vital? Es un concepto más que no añade nada a las viejas ideas animistas. Es un cambio de palabras ${ }^{23}$.

El texto donde aborda de un modo más central la figura de Bergson es Bergson y Freud, de 1939. Ahí el novelista reconoce que, aunque el psicoanalista no es un filósofo, "Bergson, evidentemente, lo es»" En relación a un artículo de Le Figaro titulado Tres filósofos octogenarios por Gaston Ragest, Baroja da cuenta de una comparación que el periodista establece entre la aparición en Occidente del Essai sur les données immédiates de la conscience de Bergson y la publicación del clásico Crítica de la razón pura de $\mathrm{Kant}^{25}$, lo que sirve a Baroja para comparar a ambos, en dos categorías de rango desigual. En la relación Bergson/Kant de Baroja podemos apreciar la distancia que Baroja encuentra entre los pensadores e intelectuales de nivel medio, por un lado, y el puesto

relativistas, Protágoras y Heráclito, los que orientan definitivamente el pensamiento de Baroja. La explicación cosmológica del segundo le satisface por lo que tiene de científica y porque concuerda con su propia visión de la vida. La teoría del devenir se convierte en la línea filosófica que dirige su obra».

20. Ibid., p. 43.

21. Ibid., p. 43.

22. Pío Baroja, Obras Completas, v. VII, Biblioteca Nueva, Madrid, 1978, p. 999.

23. Ibid. Precisamente Jacques Monod acusa de animismo metafísico a Henri Bergson en el capítulo II de Le hasard et la nécessité. Essai sur la philosophie naturelle de la biologie moderne. Seuil, 1970, pp. 25-37. Chapitre II. Vitalismes et animismes.

24. Pío Baroja, La decadencia de la cortesía y otros ensayos, Ediciones Reid, Madrid, 1956, p. 83.

25. Ibid., p. 84. «No creo que esto sea muy cierto», escribe. 
de Kant, en el más alto grado de excelencia, por el otro. «Kant se diferencia de los demás filósofos en sus condiciones y en sus propósitos» ${ }^{26} \mathrm{y}$, asevera: «Kant será siempre la estrella polar de los investigadores. No se puede comparar la obra de Bergson con la de Kant, ni por categoría, ni por intenciones. Bergson marcha con unos fines y con cierto ardor. Kant no lleva más fines que aclarar lo oscuro». A continuación, una consideración racial-antropológica muy del gusto del novelista vasco: «Kant es un báltico frío, un celta-germánico sereno y sin pasión. Bergson es ardiente y semítico» ${ }^{27}$.

Si más arriba vimos que si, por su brillantez literaria en desproporción con la profundidad filosófica, Ortega y Gasset y Bergson podrían ser comparables, el ejemplo comparativo de este pasaje será Georg Simmel. Si Kant, aunque pensador de renombre es, en el fondo «es desconocido en todas partes ${ }^{28}$, «Bergson ha podido ser popular. A veces es ingenioso y ameno. Por esta condición de amenidad, de sagacidad y de gracia, Bergson en Francia como Simmel en Alemania, han llegado a tener un gran público. Aunque Bergson sea agudo y profundo y gran escritor, no se puede comparar con Kant por ningún sentido».

La tentación del francés hacia la literatura vuelve a quedar recalcada: «En Bergson hay muchas fantasías, muchos caprichos, muchas afirmaciones gratuitas. El carácter tan diferente de estos dos filósofos hace que el uno se restrinja a lo más escueto y que el otro avance por el campo literario, donde no hay absoluta necesidad de rigor. [...] Hay que retirarse al departamento de los teósofos y de los espiritistas y hacer causa común con ellos» ${ }^{29}$. A continuación, pasará Baroja al caso del también judío Freud, con un ataque más frontal.

Más superficialmente trata Baroja la figura de Bergson en la primera parte (Las conferencias en el museo de Humour-Point, capítulo XVI) de La caverna del humorismo, de 1919, donde también se menta la condición semítica del pensador, autor de Le rire, obra que aquí se refiere expresamente:

Bergson dice que entre almas siempre sensibles, concertadas al unísono, en las que todo acontecimiento produjese una resonancia sentimental, no se conocería la risa. [...] Bergson cree que para que luego todo su efecto lo cómico, exige como una anestesia momentánea del corazón, se ve aquí cómo judío francés no puede comprender el humorismo. Nadie que haya leído a Dickens con gusto afirmará lo que afirme Bergson. Para Bergson, como para la mayoría de los franceses, la risa es siempre negadora y castigadora, es la risa del ridículo, la que señala y reprime una distracción de los hombres con relación a las generales de la sociedad ${ }^{30}$.

Según Baroja, esta visión del humorismo es enormemente restrictiva con respecto al horizonte del problema: «[...] hacer de la risa una manifestación de

26. Ibid.

27. Ibid.

28. Pío Baroja, La decadencia de la cortesía y otros ensayos, op. cit., p. 85.

29. Ibid.

30. Pío Baroja, Obras Completas, v.V, op. cit., p. 426. 
crítica social, a lo Bergson, es, sin duda, restringir la esfera de la risa y prestarle unas intenciones que no tiene más que en algunos casos »"

En una conferencia de enero de 1932 titulada El relativismo en la política $y$ en la moral Baroja hace también una breve mención a William James y Bergson: «el relativismo pragmatista, con su tendencia deliberada, reaccionaria y conservadora y sus premisas preparadas de antemano, nos interesa poco ${ }^{32}$.

Aquel carro chirriante que levanta polvo en la senda kantiana, puede extenderse a toda la filosofía contemporánea, no meramente inglesa o francesa, como dice el álter ego doctor Hurtado. La idea del post-kantismo de Pío Baroja trasluce una evidente impresión de «decadencia y falta de originalidad ${ }^{33}$. Una frase de La intuición y el estilo (esta vez en la parte tercera, El realismo) resulta muy gráfica:

«El primer alquimista de la época post-kantiana fue Hegel, y por el camino de sus sueños le siguieron Feuerbach y Karl Marx hasta Bergson $»^{34}$. En una sección previa de sus Memorias, en Galería de tipos de la época, de 1947, en el apartado intitulado Disquisiciones sobre nuestro tiempo, en torno a Ortega vuelve a extender su discurso a las mentes de las letras contemporáneas. Opina Pío Baroja: «Todo ello pasa y no queda nada»"

Simmel, Ortega y Gasset, Freud, William James, Feuerbach, Hegel, Marx (y podríamos incluir a Nietzsche, de quien más escribió entre todos ellos ${ }^{36}$ ) en el carro de los contemporáneos, los verbosos, mistificadores, frente a la estrella polar de Immanuel Kant. Para ser un «hombre de poca tenacidad» sin "preparación» para la lectura perseverante de la filosofía, tuvo una opinión muy marcada sobre los dos últimos siglos de filosofía europea.

31. Ibid, p. 425.

32. Pío Baroja, Obras Completas, v.V, op. cit., p. 913-914.

33. Carmen Iglesias, El pensamiento de Pio Baroja. Ideas centrales, op. cit., p. 66.

34. Pío Baroja, Obras Completas. v. VII, op. cit., p. 1033.

35. Ibid., p. 820.

36. Según Baroja en Nietzsche y la filosofía o en El éxito de Nietzsche, el valor extra-literario de la filosofía de Nietzsche es totalmente dependiente de la doctrina de Schopenhauer. En el primero de estos dos textos, de 1949, da cuenta de su carácter pasajero (como el resto de estos autores mentados). Con, por cierto, nulo tino profético, asegura que «cuando aquí [España] se traduzcan sus obras, si es que se traducen, Nietzsche habrá pasado de moda». Obras Completas, v. VIII, Biblioteca Nueva, Madrid, 1980, p. 856. 